Final version published in Gender \& Society

https://doi.org/10.1177/0891243220948220

\title{
Gendered Places: The Dimensions of Local Gender Norms Across the U.S.
}

\author{
William J. Scarborough \\ University of North Texas \\ Ray Sin \\ Early Warning Services
}

\begin{abstract}
In this study, we explore the dimensions of local gender norms across U.S. commuting zones. Applying hierarchical cluster analysis with four established indicators of gender norms, we find that these local cultural environments are best conceptualized with a multilevel framework describing gender norms across varying levels of detail. Broadly, commuting zones can be differentiated between those that are egalitarian and those that are traditional. Within these general categories, however, exist more complex dimensions. Gender traditional areas may be distinguished between traditional-breadwinning and traditional-essentialist, while egalitarian areas are separated into those that are liberal-egalitarian and egalitarian-essentialist. Examining the factors sustaining this spatial variation, we test the role of compositional and contextual effects. We find limited support for compositional effects, as commuting zone demographic makeup explains little variation in gender norm indicators. Instead, we find evidence that local gender norms are sustained through contextual effects where the experience of living in a particular environment shapes residents' attitudes and behaviors. Contextual effects are exceptionally strong in areas with traditional gender norms, where residents who would otherwise hold gender egalitarian perspectives (e.g. the highly educated) have more traditional outlooks than those who share the same characteristics, but reside in places with egalitarian gender norms.
\end{abstract}

\section{Authors' Note:}

Some of the data used in this article are derived from Sensitive Data Files of the GSS, obtained under special contractual arrangements designed to protect the anonymity of respondents. These data are not available from the authors. Persons interested in obtaining GSS Sensitive Data Files should contact the GSS at GSS@NORC.org. 


\section{Gendered Places: The Dimensions of Local Gender Norms Across the U.S.}

Travelers moving across the U.S. revel at the cultural diversity within the nation. From the buzz of New York, NY to the heartland charm of Lincoln, NE to the eccentricity of San Francisco, CA, each place has a unique cultural reputation (see Florida 2014; Molotch et al. 2000). In addition to these well-known attributes, however, research has also shown that gender norms vary in meaningful ways across the country (Abelson 2019; Brown-Saracino 2017; Scarborough, Sin, and Risman 2019). Gender attitudes tend to be more egalitarian in the Northeast and traditional in the South (Scarborough et al. 2019). Gender stereotypes of women's nurturance and men's agency are more salient in middle-America than coastal states like Massachusetts (Correll et al. 2017). Even individuals' expressions of masculinity (Abelson 2019) and sexual identity (Brown-Saracino 2017) have been found to be sensitive to local ideologies. Across a multitude of studies and methodological approaches, scholars have consistently identified the omnipresent role of local norms in shaping social life (see Chatillon, Charles, and Bradley 2018; Horne and Mollborn 2020).

Despite receiving significant attention as a social force, little research has examined the multidimensional structure or patterns of spatial variation in local gender norms across the U.S. Instead, studies exploring the dimensions of gender norms have focused primarily on crossnational variation (Charles and Grusky 2004; Grunow, Begall, and Buchler 2018; Knight and Brinton 2017). These works leverage the fact that nations have discrete borders and identities by which to compare gender norms. However, case study research has shown evidence for the presence of more localized gender norms. Many studies have identified differences in norms between rural and urban areas (Evans 2019), while others have documented how local gender 
norms shape individuals' attitudes and patterns of behavior (Brown-Saracino 2017; Correll et al. 2017; Guenther 2010). Taken together, research on the consequences of gender norms has focused on local dynamics, while studies on spatial variation have primarily examined countrylevel attributes. As a result, there is little research on sub-national patterns of variation in gender norms and the dimensions by which these local attributes are constituted.

In this study, we explore the dimensions of gender norms across the U.S., focusing on variation between commuting zones where individuals live and work (Fowler et al. 2019). We use hierarchical cluster analysis to examine how commuting zones cluster based on shared characteristics of four observed variables that have been established in previous research as indicators of gender norms. Combining both attitudinal ideologies and revealed preferences, these gender norm indicators include: Support for women in politics (obtained from the General Social Survey [GSS] 2006 through 2016), gender segregation in field of bachelor's degree (2017 American Community Survey [ACS] five-year sample), mothers' age at first birth (2017 ACS five-year sample), and views toward the gendered division of household labor (GSS 2006 through 2016).

Our application of hierarchical cluster analysis allows for a dynamic approach to conceptualizing the structure of gender norms whereby each cluster division represents a tradeoff between parsimony and nuance. Judging levels of dissimilarity between clusters reveals two useful frameworks. At the broadest level, local gender norms in the U.S. can be conceptualized as either egalitarian or traditional. Further detail, however, reveals that there are different types of traditional and egalitarian areas. Egalitarian commuting zones can be divided into those emphasizing women's independence (liberal-egalitarian) and those with persistent beliefs of essential difference between women and men (egalitarian-essentialist). Traditional commuting 
zones can also be divided into two groups, with some areas characterized by pronounced opposition to women's participation in the public sphere of work/politics (traditionalbreadwinner) and others where women's public sphere participation is somewhat supported, but is expected to occur in separate fields from men (traditional-essentialist).

After identifying these four clusters of gender norm environments, we then examine how this spatial variation is sustained. We test two competing explanations. First, differences between commuting zones may be due to compositional effects (Gallego et al. 2016; Maxwell 2020). From this perspective, commuting zones have distinct gender norms due to demographic differences in the types of people who reside there. A second explanation asserts that areas' norms are maintained through contextual effects (Johnston and Pattie 2006; Maxwell 2019). From this perspective, the experience of residing in a particular location makes individuals hold perspectives that are in alignment with the norms where they live. We use two established methods to test compositional versus contextual effects (see Maxwell 2019). First, we apply a series of regression models to examine whether demographic compositional differences between the four clusters account for variation between them in gender norm indicators. Second, we examine differences in gender norm indicators across clusters for individuals who hold the same demographic characteristics (e.g. college degree holders) to test whether the spatial context associated with each cluster causes individuals' perspectives to deviate from what would be expected based on their personal characteristics alone.

We find that contextual effects play a larger role than compositional effects in sustaining spatial variation in gender norms. This is particularly true in traditional-breadwinner and traditional-essentialist commuting zones, where individuals who would be expected to have more gender egalitarian behaviors/attitudes (e.g. the college educated) are much more traditional in 
their outlooks. There was some evidence that compositional effects contribute to liberalegalitarian gender norms. Yet, even after accounting for demographic differences, residents of these commuting zones are still found to have attitudes and behaviors that are the most supportive of gender equality. These findings shed light on the important role of space in sustaining gendered cultural dynamics in the U.S., as the contexts where individuals live and work convey values and expectations that are embodied in individuals' perspectives and actions.

\section{FROM GLOBAL TO LOCAL: SPATIAL VARIATION IN GENDER NORMS}

As opposed to individual-level orientations, norms are the collective expectations of attitudes and behaviors associated with a particular context (Horne and Mollborn 2020; Pearse and Connell 2016). Norms convey what is appropriate to do, say, or feel within a setting. Gender norms pertain to the set of expectations differentiating conduct between women and men (Pearse and Connell 2016). Widespread beliefs that women are better caregivers than men, for example, constitute powerful norms resulting in women's greater time spent providing childcare and their disproportionate representation in care occupations (Ridgeway 2011). It is important to note that norms are qualities of collectivities and not deterministic of individuals' behavior. While, in the aggregate, attitudes and behavior align with norms, individuals express agency in reacting against and often challenging these cultural constraints (Kabeer 2002; Risman 2004).

One common method to study gender norms is examining their cross-national variation. Researchers have argued that differences between nations in both gender attitudes and patterns of behavior between women and men reflect distinct contexts of gender norms (Charles and Grusky 2004; Inglehart and Norris 2003). Many have conceptualized these cross-national differences with a unidimensional scale where countries range from having traditional to egalitarian norms (Baizan, Arpino, and Delclòs 2016; Inglehart and Norris 2003). Traditional norms prescribe 
strict gendered divisions of labor where men are decision-makers and breadwinners while women tend to home and children. On the other side of the spectrum, egalitarian norms convey gender equality in both decision-making and the division of labor. Yet, research over the past two decades has critiqued this unidimensional approach on the basis that there are important differences in norms directed toward separate aspects of society (Charles and Grusky 2004; Grunow et al. 2018; Knight and Brinton 2017). Comparative studies across industrialized nations, for example, have identified dimensions of gender norms that are unique to family contexts, employment, individualism, and notions of essential difference between women and men (Charles and Bradley 2009; Goldscheider, Bernhardt, and Lappegård 2015; Grunow et al. 2018; Knight and Brinton 2017). These studies suggest that nation-level gender norms are multidimensional. Nations may be egalitarian in some respects (supporting women's employment) while remaining traditional in others (endorsing women's primary role as family caregivers).

Cross-national research has advanced our understanding of gender norms by identifying their spatial variation and providing theoretical tools to conceptualize their cultural dimensions. These works take advantage of the fact that nations have recognized borders with clear demarcations of culture and identity. Yet, a growing number of studies have identified the presence of more localized gender norms. Research in Africa (Charles 2019; Evans 2018) and Southeast Asia (Evans 2019) has identified differences between rural areas with more traditional gender norms and urban centers where women's educational advancement and employment are widely supported. Many studies have compared the gender norms between East and West Germany (Dirksmeier 2015; Guenther 2010). In the U.S., comparative case studies have examined how local gender norms shape the salience of stereotypes (Correll et al. 2017), 
personal identity (Brown-Saracino 2017), self-presentation (Abelson 2019), and feminist organizing (Crossley 2017).

There is growing evidence from qualitative and case study research that sub-national local gender norms play a large role in individuals' lives. Yet, the case study approach of this research is inherently limited in describing the structure of gender norms across localized settings. For these types of questions, quantitative research examining a larger number of places provides a suitable complement. Presently, however, the majority of research examining the structure of spatial variation in gender norms has been cross-national and focused on gender norms associated with countries as a whole. Therefore, this study aims to build from recent case studies highlighting the importance of local gender norms by examining their broader variation and dimensional structure across a larger set of commuting zones within the U.S.

Our approach is informed by cross-national research that has conceptualized gender norms as both uni- and multidimensional. Instead of viewing these frameworks as competing, however, we suggest that there may be greater value in balancing the nuance of multidimensionality with general description offered by unidimensional perspectives (Healy 2017). It is possible that simple and complex models may be complementary such that unidimensional understandings of gender norms can be broken down into greater detail. Such hierarchical conceptualizations of gender norms have not been used in previous research, though there is initial evidence for its applicability. Knight and Brinton (2017), for example, find that there exists not one, but multiple forms of egalitarianism across European nations. Mandel (2009) also found that nations cluster in varying levels of detail according to patterns of gender inequality. While not explicitly studying the hierarchical relationship between different theoretical frameworks, these studies do suggest complementarity between the less detailed 
unidimensional frameworks and the more complex multidimensional approaches by showing how broad conceptualizations of high- versus low-equality contexts can be subdivided and characterized at greater detail. Applying these insights to the U.S., we examine whether uni- and multidimensional frameworks for gender norms may be useful in first conceptualizing places as either traditional or egalitarian, and then offering further detail on multidimensional heterogeneity.

\section{WHAT SUSTAINS LOCAL GENDER NORMS? COMPOSITION VERSUS CONTEXT}

If gender norms have local variation, where does it come from and how is it sustained? Existing research suggests two possibilities. First, spatial variation in gender norms may result from differences in the types of people who reside in certain locations - otherwise known as compositional effects (Maxwell 2019, 2020). Research has shown that highly educated individuals, for example, are more likely to support women's employment and the equal sharing of housework between women and men (Meagher and Shu 2019; Scarborough et al. 2019). If these individuals make up a larger share of the population in some locations than others, this may contribute to unique gender norms through differences in demographic composition.

The second possible mechanism sustaining spatial variation stems from contextual effects where the experience of living in a particular location makes people embody attitudes and behaviors consistent with local norms (Maxwell 2019). Qualitative studies have provided early evidence for contextual effects by showing how exposure to gender norms can change individuals' outlook over time. Evans (2019), for example, found that rural women's migration to urban centers in Cambodia coincided with greater support for women's education and employment as they increasingly interacted with women in leadership and men who contributed to family labor. In the U.S., qualitative comparative studies have found that areas' cultural norms 
can shape individuals' sense of sexual identity (Brown-Saracino 2017) and masculinity (Abelson 2019) by providing a set of expectations around how individuals self-present and interact.

Existing research points to the possibility for both compositional and contextual dynamics to influence variation in local gender norms. Therefore, in addition to investigating the structure of local gender norms in the U.S., we also examine the role of these two mechanisms in sustaining this spatial variation.

\section{METHODS}

\section{Geographic Unit of Analysis}

We use commuting zones as our unit of analysis because these units constitute the least permeable geographic context in the U.S., making them ideal for the study of local norms. As spaces where people live and work, commuting zones contain both the economic and normative environment for residents' lives. In delineating commuting zones, we use labor sheds defined by the Bureau of Economic Analysis (Fowler 2019) that maximize the degree to which commuting patterns are contained in a geographic space. In 2010, for example, 93 percent of residents lived and worked within the boundaries of a labor shed, higher than the definitions for any other geospatial unit (Fowler, Jensen, and Rhubart 2019). We use the most recent definitions demarcating 179 labor sheds across the U.S. Of these, the sample is restricted to 82 labor sheds represented in the data used to measure gender norms. Our sample is illustrated in Figure 1. While a considerable number of labor sheds are not included in the analysis, the majority (82.4 percent) of the U.S. population resides in the 82 labor sheds analyzed here. 


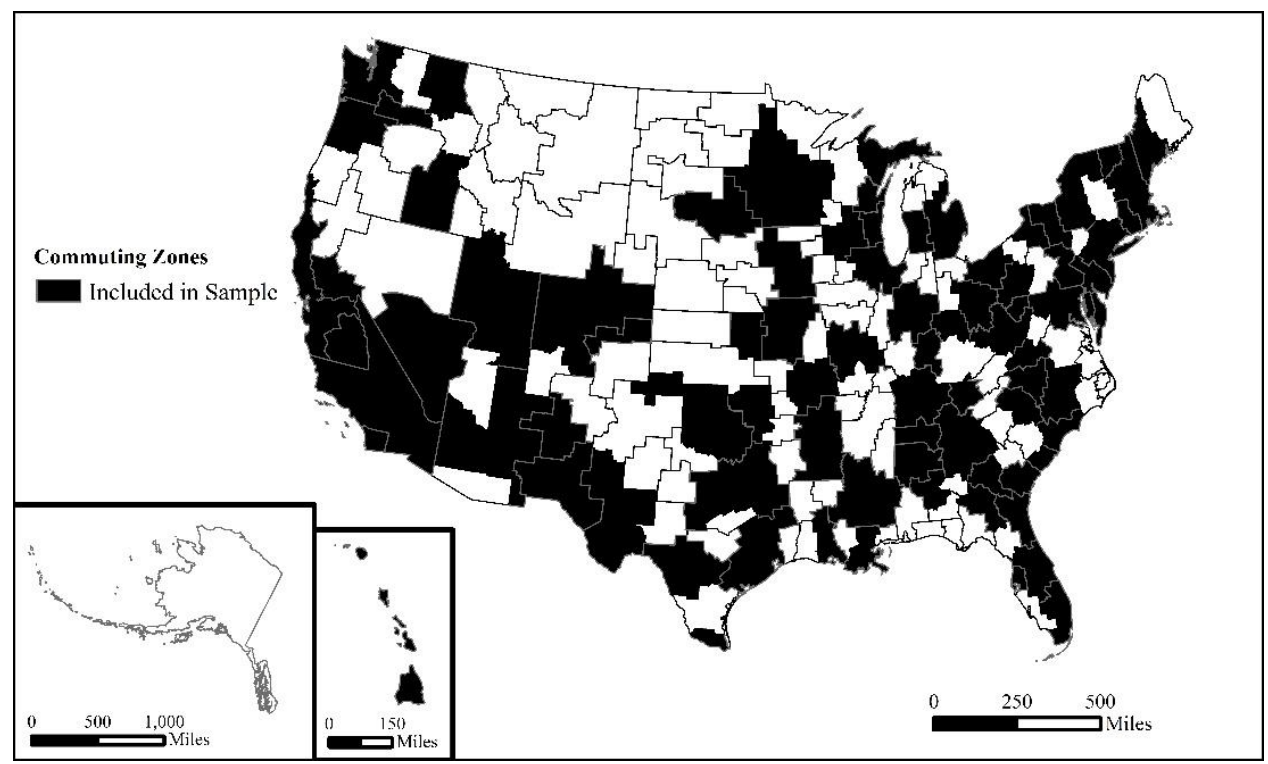

FIGURE 1: Commuting Zones Included in Sample

\section{Analytic Approach}

In this study, we use hierarchical cluster analysis (HCA), which is designed to group units together based on shared characteristics of observed variables. In the agglomerative approach used here, ${ }^{1}$ commuting zones begin as single entities and are grouped with other units/clusters based on maximal similarity until all units are within a single cluster. Meaningful groupings are identified as sets of clusters that are highly dissimilar from the set preceding it. For the purposes of this study, HCA was chosen for three reasons. First, HCA is an inductive approach where the structure of gender norms are not defined a priori, but are allowed to emerge empirically in the course of data analysis. Relatedly, HCA's inductive approach to modeling heterogeneous distributions also allows for an examination of the different dimensions of gender norms through comparing indicator means across identified clusters. Third, the agglomerative method of HCA allows for the identification of stable hierarchical structures. This is an advantage of HCA over latent class analysis, which does not use agglomerative or divisive 
models and is, therefore, less suited for examining relationships between different analytical levels of clustering.

\section{Operationalization of Local Gender Norms}

Norms are symbolic in nature, conveying widespread expectations of what is acceptable or unacceptable in a particular context (Coleman 1994; Pearse and Connell 2016; Horne and Mollborn 2020). As symbols and cultural messages are difficult to quantify in spatialcomparative studies, scholars have inferred the structure of norms through their reflection in both patterns of behavior and average social attitudes (see Horne and Mollborn 2020). Grunow and colleagues (2018), for example, describe nation-level gender norms through examining crossnational variation in responses to survey items measuring gender attitudes (see also Charles and Grusky 2004; Knight and Brinton 2017). Others have focused on cross-national differences in behavioral patterns reflecting revealed preferences. Lesthaeghe (2010, also see Goldscheider et al. 2015) used fertility rates and delayed parenthood as a reflection of cultural norms, while Charles and Bradley (2009, also see Barone 2011) examined nation-level patterns of gender segregation in university field of study. Drawing from this body of research, we use four established indicators of gender norms that cover both attitudinal and behavioral patterns.

First, following research examining gender norms directed toward the public sphere (Meagher and Shu 2019; Scarborough et al. 2019), we use an item from the General Social Survey $^{2}$ (Smith et al. 2017) measuring respondents' disagreement (agree, disagree) with the statement: Most men are better suited emotionally for politics than are most women. While this item is specifically focused on politics, previous research has found that individuals' assessments of political leadership reflect broader beliefs about leadership qualities and competencies that apply generally across the public sphere of work (Dolan 2014; Thomas and Wilcox 2014). 
Because the GSS surveys between 1,000 and 2,000 respondents every two years, we used data for each biennial survey year from 2006 through 2016 to increase sample sizes within commuting zones. Our total sample of GSS respondents for this item is 9,008. Respondents were matched to commuting zones based on county of residence, since county boundaries do not intersect commuting zones (Fowler et al. 2019). Aggregating to commuting zones, we calculated the year-adjusted ${ }^{3}$ proportion of respondents who disagreed with the statement that women are unsuited for politics as a measure of commuting zone support for gender equality in the public sphere.

The second indicator draws from previous research showing that gender norms of essential difference manifest in women's and men's selection of college majors (Barone 2011; Charles and Bradley 2009). We aggregate county-level data from the 2017 American Community Survey five-year sample ${ }^{4}$ (Manson et al. 2019) to calculate each commuting zone's index of dissimilarity measuring the gender segregation of field of bachelor's degree for college degree holders aged 25 years or older. ${ }^{5}$ The index of dissimilarity is one of the most common measures of segregation (Dickerson, Schur, and Blasci 2010; Taylor 2019), and is calculated as the summed absolute difference in the number of women and men across fields of study relative to their overall population among college degree holders. Estimates from the index are interpreted as the percentage of women and men that would have to change educational fields for there to be perfect gender integration, with a score of zero indicating perfect integration and a score of one reflecting absolute segregation. Although this item includes only those with a college degree, the sampled population is consistent across commuting zones, making it suitable for spatial comparisons. 
As a third indicator, we draw upon research that has used trends in fertility and delayed parenthood as an indicator of increasing acceptance toward women's independence and decisionmaking (Gerson 2010; Goldscheider et al. 2015; Lesthaeghe 2010). Capturing this aspect of gender norms, we calculated the average age of women's first birth for each commuting zone using individual-level data from the 2017 ACS five-year Public Use Microdata Series (PUMS) (Ruggles et al. 2019). We use PUMS data because aggregate-level data provided only age categories (e.g. first birth at age 20 to 30) that prevented the calculation of commuting zone averages. PUMS respondents were assigned to commuting zones by geospatially matching PUMAs (Public Use Microdata Areas) to commuting zones. In the few instances where PUMAs straddled the borders of commuting zones (less than a tenth of the population), we adopted the approach used in previous research (Autor and Dorn 2013; Dorn 2009) and weighted respondents based on the likelihood of belonging to a commuting zone, calculated from the proportion of PUMA population residing in each commuting zone, determined at the censusblock level with the Geocorr application from the Missouri Census Data Center (2018).

Finally, the fourth indicator comes from an additional item in the GSS that has been used to measure gender norms directed toward the private sphere of the family (Scarborough et al. 2019). This item measures respondents' disagreement (strongly agree, agree, disagree, strongly disagree) with the statement: It is much better for everyone involved if the man is the achiever outside the home and the woman takes care of the home and family. As with the other GSS item, we used data from surveys conducted from 2006 through 2016 to increase sample sizes within commuting zones. The total sample of respondents for this item was 9,412. After rescaling the variable to range from zero to one and assigning respondents to commuting zones based on county of residence, we calculated the year-adjusted ${ }^{6}$ average response to this item for each 
commuting zone as an indicator of gender norms directed toward the private sphere. Higher scores on this measure reflect greater local support for equal family responsibilities between women and men.

Collectively, our four indicators include both attitudinal and behavioral patterns that have been used extensively in the study of gender norms. By including these items together, we better account for the multiple ways that gender norms are reflected in social life. Commuting zones with fewer than 30 respondents represented in the GSS data were dropped. ${ }^{7}$ The final sample includes 82 commuting zones representing 82.4 percent of the U.S. population. A summary of each variable, its associated data source, and descriptive statistics are provided in the appendix, Table A1. When conducting HCA, we transform all indicators into a common scale. In general, scholars have advised against using Z-scores in HCA and, instead, recommend standardizing indicators according to their range (Brusco et al. 2017). Following these guidelines, each indicator, $X$, was standardized to $Z$, through taking its difference from the minimum and dividing it from the range: $Z=(X-\operatorname{Min}(\mathrm{X})) /(\operatorname{Max}(\mathrm{X})-\operatorname{Min}(\mathrm{X}))$.

\section{Cluster Identification}

We use a dendrogram to visualize and interpret the results of the HCA, where commuting zones are organized as a clustering tree with consecutively more similar commuting zones being grouped together. We test the statistical significance of clustering using the Significance of Hierarchical Clustering (SHC) method proposed by Kimes et al. (2017) that provides sequential tests of whether clusters are meaningfully different from what would be expected due to sampling variation. This approach accounts for the inflated family-wise error rate associated with HCA (Loop and McClure 2015) by adjusting alpha levels by cluster sample size and imposing a 
stopping rule so that no further tests are conducted after a parent cluster is found to be nonsignificant (see Kimes et al. 2017).

After identifying meaningful clusters, we then characterize them by comparing indicator means. We use Cohen's D, the standardized difference between clusters in each indicator, to measure the size of differences between clusters. We follow Ferguson's (2009) interpretation and identify values around .41 to represent minimal differences, 1.15 as moderate, and 2.70 as large. We focus primarily on effect sizes because they are not sensitive to differences in the number of commuting zones belonging to each cluster (Cutter 2020). We also report ANOVA tests of between-cluster differences in indicators.

\section{Testing Composition Versus Context as Contributors to Local Gender Norms}

In the results below, HCA uncovered four primary clusters of local gender norms. After identifying these clusters, we use two procedures that have been applied in previous research (Gimpel et al. 2020; Maxwell 2019) to examine the relative strengths of compositional and contextual effects in explaining spatial variation in norms. In each approach, we merged commuting-zone clusters from the HCA to individual-level data from the GSS and ACS to examine how clusters predicted respondent outcomes associated with gender norm indicators. Each outcome represents the gender norm indicator used in HCA at the individual-level (see appendix, Table A1). One exception is respondents' possession of a bachelor's degree in a science/engineering field. The commuting zone indicator associated with this individual-level outcome is gender segregation in field of bachelor's degree. Because gender segregation can only be measured in the aggregate, we use the possession of a degree in science/engineering as the associated individual-level outcome, as women are less likely than men to study this field 
(U.S. Census Bureau 2012). Details on individual-level variables are reported in the appendix, Table A1.

We first examine the role of compositional effects through using a series of regression models that test whether differences in gender norm indicators between clusters are due to characteristics of the types of residents in each location. We use average marginal effects ${ }^{8}$ calculated from logistic regression for binary outcomes (disagree that women are unsuited for politics, bachelor's degree in science/engineering) and OLS regression coefficients for continuous outcomes (mothers' age of first birth, level of disagreement that men should work and women tend home). For each of the four outcomes, we first estimate the effects of residing in each cluster with a baseline model including only fixed effects for region (Northeast, Midwest, South, and West) and survey year. Then, in a second model we add demographic controls that have been found in previous research to be associated with gender egalitarian perspectives and behaviors (see Cotter et al. 2011; Scarborough et al. 2019; Shu and Meagher 2018). These include education (high school degree or less, some college, college degree or more), occupation (managerial/professional, service, sales/office, natural resources/construction, production/transportation, no occupation), age, employment status (full-time, part-time, unemployed, not in labor force), race (Black, Latinx, White, Other), and marital status (married, separated/divorced/widowed, never married). If cluster differences in gender norm indicators are due to compositional effects, we expect the coefficients for clusters to reduce substantially and become non-significant after adding demographic controls.

Second, we examine the role of contextual effects by testing whether respondents with the same characteristics have varying outcomes across clusters on individual-level gender norm indicators. We use the same regression models used to explore compositional effects, and add an 
interaction term to determine whether the effects of demographic variables differ by cluster. Because education has been found to be a strong predictor of gender attitudes and delayed parenthood (Lesthaeghe 2010; Scarborough et al. 2019), we interact education with cluster to predict attitudes toward women's suitability for politics, mothers' age at first birth, and attitudes toward the gendered division of family labor. We report the predicted difference between high school or less and college educated respondents from these models. Evidence for contextual effects are observed if the education gap in outcomes differs by cluster, indicating that spatial variability in gender norms is due, at least in part, to differences in the perspectives of individuals with the same level of education rather than their uneven distribution across commuting zones. In predicting the possession of a bachelor's degree in science/engineering fields, our sample is restricted to college educated women. Therefore, in this analysis we explore whether the share of commuting zone workers employed in science and engineering occupations predicts field of study similarly across gender norm clusters. Data on science/engineering occupational concentration are from the 2017 ACS five-year sample. We compare predicted probabilities of studying a science/engineering field for residents in commuting zones at the $25^{\text {th }}$ percentile ( 4 percent employed in science/engineering occupations) and $75^{\text {th }}$ percentile (6 percent) of science/engineering occupational concentration. Evidence for contextual effects are observed if the relationship of science/engineering occupational concentration to field of study varies by cluster, indicating that the effects of the supply of science/engineering occupations on women's field of study depends on the local context of gender norms. 


\section{RESULTS}

\section{The Structure of Local Gender Norms}

Figure 2 illustrates the results of the HCA with a dendrogram. Three features of Figure 2 are used for interpretation. First, the vertical ordering of commuting zones provides one indicator of difference. For example, the two most different commuting zones on the selected indicators are Albany, GA and San Francisco, CA. Second, the length of horizontal lines provides a measure of difference between levels of clustering. These lengths are measured by the squared Euclidean Distance indicating differences in the sum of squares for clusters at varying divisions. Third, statistical significance of clustering is indicated by the boldness of the lines associated with each division. Bold lines indicate significant clustering at the $\mathrm{p}<.05$ level.

Two key breaks are observed in Figure 2. Examining the first substantial cluster, the longest horizontal lines are found at the least detailed level of clustering where commuting zones are divided into two groups. This initial division is significant $(\mathrm{p}<.05)$. Substantive differences in the means for each cluster in the range-standardized indicators $(Z)$ used in HCA are illustrated in the top panel of Figure 3, and unstandardized means for each indicator are reported in Table 1. 27 commuting zones have traditional gender norms. These areas show more opposition to women's suitability for politics, have higher levels of gender segregation in college majors, have lower average age of mothers' first birth, and have lower support for gender equality in the private sphere of the family. Examples of traditional commuting zones include Grand Rapids, MI, Houston, TX, Little Rock, AR, Salt Lake City, UT, and Spokane, WA. Conversely, 55 commuting zones have higher levels for each standardized indicator and are labelled as egalitarian. These include areas such as Boston, MA, Madison, WI, Portland, ME, Savannah, GA, and Seattle, WA. 


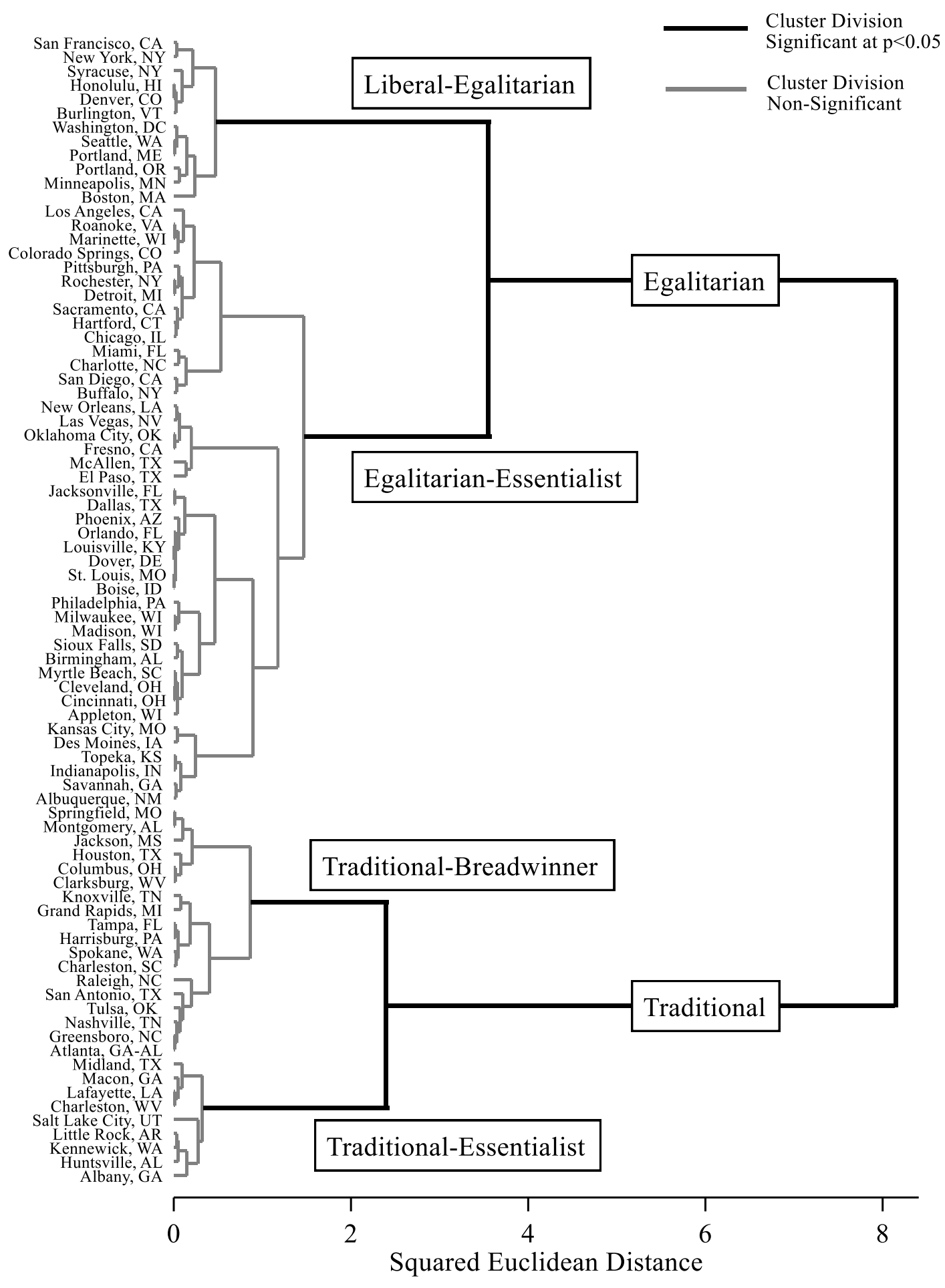

FIGURE 2: Dendrogram Illustrating the Structure of Gender Norms Across U.S. Commuting Zones

NOTE: Commuting zones identified by principal city. 


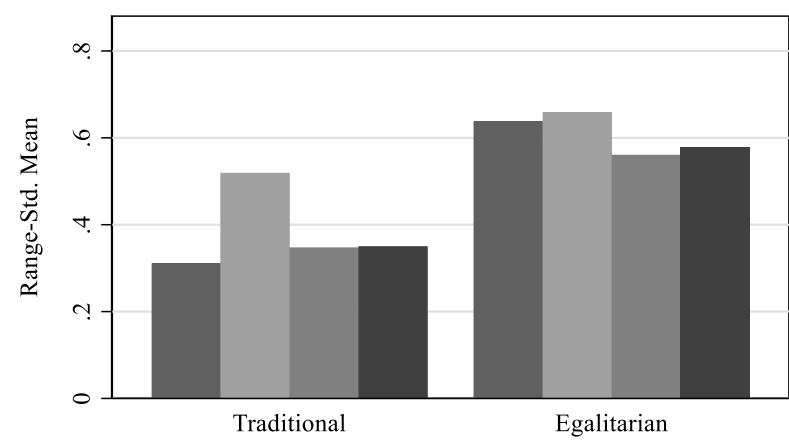

Range-Standardized Indicators Disagree, Men Better Suited for Politics than Women

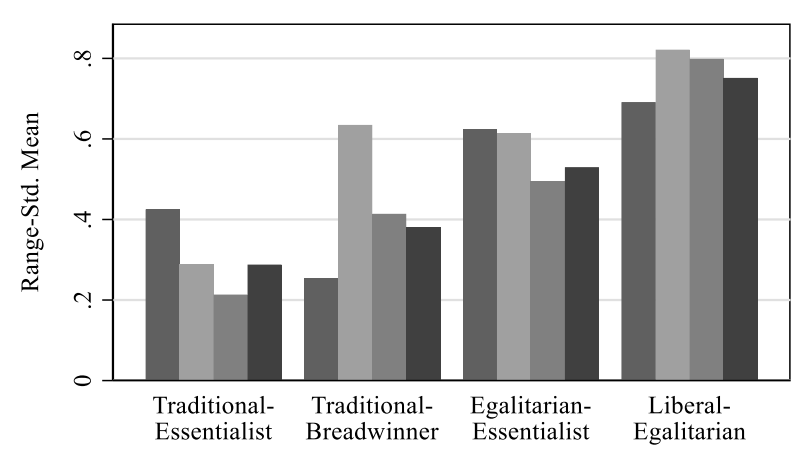

Segregation of
College Major (I

Segregation of
College Major (Inverse) First Birth

Disagree, Better

for Men to Work,

Women Tend Home

\section{FIGURE 3: Range-Standardized Means of Gender Norm Indicators Across Clusters}

Examining the size of differences between the clusters, Cohen's D surpasses the threshold for meaningful effect sizes across all indicators and ANOVA tests show these differences are significant $(\mathrm{p}<.01)$. Large effect sizes are observed in views toward women in politics, suggesting that gendered expectations around women's public sphere leadership constitute a major point of divergence between egalitarian and traditional commuting zones. Moderate differences are found in age of first birth and views toward the private sphere division of labor. Differences are least pronounced in the segregation of college majors. This is consistent with research showing that norms of gender essentialism persist even among segments of society that are egalitarian in most other ways (Cotter et al. 2011). 
TABLE 1: Unstandardized Means of Gender Norm Indicators and Differences Between Clusters

\begin{tabular}{|c|c|c|c|c|c|c|}
\hline 2 Cluster & $\begin{array}{c}1 \\
\text { Traditional } \\
\end{array}$ & $\begin{array}{c}2 \\
\text { Egalitarian }\end{array}$ & $\begin{array}{l}\text { Group } \\
\text { Difference } \\
(d) \\
\end{array}$ & $\begin{array}{l}95 \% \text { CI for } \\
\text { Group } \\
\text { Difference }\end{array}$ & $\begin{array}{l}\text { ANOVA F- } \\
\text { Test }\end{array}$ & p-value \\
\hline $\begin{array}{l}\text { Disagree, Men Better Suited for } \\
\text { Politics than Women }\end{array}$ & 0.724 & 0.775 & 2.50 & $(1.89-3.09)$ & 112.93 & 0.000 \\
\hline Segregation of College Majors & 0.259 & 0.242 & 0.78 & $(0.30-1.26)$ & 11.06 & 0.001 \\
\hline Average Age of First Birth & 26.54 & 27.32 & 1.17 & $(0.67-1.66)$ & 24.84 & 0.000 \\
\hline $\begin{array}{l}\text { Disagree, Better for Men to } \\
\text { Work, Women to Tend Home }\end{array}$ & 0.546 & 0.586 & 1.35 & $(0.84-1.85)$ & 32.87 & 0.000 \\
\hline $\mathrm{N}$ (Commuting Zones) & 27 & 55 & & & & \\
\hline Traditional Clusters & $\begin{array}{c}1 \\
\text { Traditional- } \\
\text { Essentialist }\end{array}$ & $\begin{array}{c}2 \\
\text { Traditional- } \\
\text { Breadwinner }\end{array}$ & $\begin{array}{l}\text { Group } \\
\text { Difference } \\
(d)\end{array}$ & $\begin{array}{l}95 \% \text { CI for } \\
\text { Group } \\
\text { Difference }\end{array}$ & $\begin{array}{l}\text { ANOVA F- } \\
\text { Test Between } \\
\text { Traditional } \\
\text { Clusters }\end{array}$ & p-value \\
\hline $\begin{array}{l}\text { Disagree, Men Better } \\
\text { Suited for Politics than } \\
\text { Women }\end{array}$ & 0.742 & 0.716 & 1.43 & $(0.53-2.31)$ & 12.28 & 0.002 \\
\hline $\begin{array}{l}\text { Segregation of College } \\
\text { Majors }\end{array}$ & 0.287 & 0.245 & 2.69 & $(1.59-3.77)$ & 43.58 & 0.000 \\
\hline Average Age of First Birth & 26.05 & 26.79 & 1.73 & $(0.78-2.64)$ & 17.88 & 0.000 \\
\hline $\begin{array}{l}\text { Disagree, Better for Men to } \\
\text { Work, Women to Tend } \\
\text { Home }\end{array}$ & 0.535 & 0.551 & 0.60 & $(0.22-1.41)$ & 2.17 & 0.153 \\
\hline $\mathrm{N}$ (Commuting Zones) & 9 & 18 & & & & \\
\hline Egalitarian Clusters & $\begin{array}{l}\quad 3 \\
\text { Egalitarian- } \\
\text { Essentialist }\end{array}$ & $\begin{array}{c}4 \\
\text { Liberal- } \\
\text { Egalitarian }\end{array}$ & $\begin{array}{l}\text { Group } \\
\text { Difference } \\
\quad(d)\end{array}$ & $\begin{array}{l}95 \% \text { CI for } \\
\text { Group } \\
\text { Difference }\end{array}$ & $\begin{array}{l}\text { ANOVA F- } \\
\text { Test Between } \\
\text { Egalitarian } \\
\text { Clusters }\end{array}$ & p-value \\
\hline $\begin{array}{l}\text { Disagree, Men Better } \\
\text { Suited for Politics than } \\
\text { Women }\end{array}$ & 0.773 & 0.783 & 0.54 & $(0.11-1.19)$ & 2.78 & 0.101 \\
\hline $\begin{array}{l}\text { Segregation of College } \\
\text { Majors }\end{array}$ & 0.248 & 0.223 & 1.49 & $(0.78-2.18)$ & 20.84 & 0.000 \\
\hline Average Age of First Birth & 27.08 & 28.19 & 2.01 & $(1.26-2.75)$ & 37.83 & 0.000 \\
\hline $\begin{array}{l}\text { Disagree, Better for Men to } \\
\text { Work, Women to Tend } \\
\text { Home }\end{array}$ & 0.577 & 0.616 & 1.49 & $(0.79-2.19)$ & 20.88 & 0.000 \\
\hline $\mathrm{N}$ (Commuting Zones) & 43 & 12 & & & & \\
\hline
\end{tabular}

NOTE: $d=$ Cohen's D, reported as absolute values. 
Beyond the initial two-cluster break, the dendrogram illustrates other important differences. Specifically, the next largest division separates traditional commuting zones into two clusters and egalitarian commuting zones into two clusters. Both of these second-order divisions are significant $(\mathrm{p}<.05)$. Interpretation of these groups can be made through examining means of the range-standardized indicators $(Z)$ used in HCA (bottom panel of Figure 3), and levels of the unstandardized indicators (Table 1). The most traditional areas of the U.S., those located at the bottom of the dendrogram, can be characterized as having traditional-essentialist norms. The nine commuting zones in this cluster include places such as Charleston, WV and Huntsville, AL. Here, gender segregation of college majors is at the highest levels, reflecting strong norms of gender essentialism. Coupled with this, women give birth at a younger age in these commuting zones, and expectations around the familial division of labor are more traditional. Relatively more egalitarian norms, while still trending traditional, are found with regards to average levels of support for gender equality in the public sphere (measured by disagreement that women are unsuited for politics).

The next cluster contains 18 commuting zones and can be described as having traditional-breadwinner norms. Locations in this group include Knoxville, TN and Tulsa, OK. More than any other cluster, these commuting zones show the least support toward gender equality in the public sphere. This is coupled with traditional views toward the gendered division of family labor, and below-average age of women's first birth. Yet, these commuting zones have lower levels of gender segregation in field of study, suggesting that gender essentialism is less prominent.

Examining differences in indicator means between the two traditional clusters reveals points of divergence and similarity. Both traditional clusters espouse similar expectations for the 
gendered division of family labor, indicating that traditional private sphere gender norms are a unifying characteristic of both traditional clusters. Significant $(p<.01)$ differences are observed for the remaining indicators, but effect sizes vary. Large differences are observed in the segregation of college major selection, where women and men are more likely to have studied different fields in traditional-essentialist areas. This indicates that levels of gender essentialism are a point of distinction between the two traditional clusters. Moderate differences are observed in age of first birth, where women delay parenthood somewhat longer in traditionalbreadwinning areas. Although traditional-essentialist commuting zones have higher levels of college major segregation and younger age of first birth, they also espouse greater support for women in politics than traditional-breadwinning locations. This suggests that gender norms in traditional-essentialist areas convey that women may advance, but in different domains as men and while also continuing to manage the home/family. In contrast, traditional-breadwinning norms are based more on expectations that women are less suitable for public sphere participation than on essentialist beliefs of gender difference.

Broadly defined egalitarian areas are also subdivided into two clusters. 43 commuting zones have egalitarian-essentialist norms and include places such as Milwaukee, WI, and Orlando, FL. These areas mirror the general patterns found among traditional-essentialist commuting zones, but trend much more egalitarian. There are higher levels of support for women's public sphere leadership and the equal participation of women and men in the family. Age of first birth is much higher than traditional-essentialist areas, and slightly higher than traditional-breadwinner commuting zones. The gender segregation of college majors, representing norms of gender essentialism, is actually slightly higher than traditionalbreadwinner areas. Collectively, these trends suggest egalitarian-essentialist commuting zones 
are characterized by high support for women's participation in work/politics, alongside continued expectations that these occur in different domains as men (albeit, to a lesser extent than traditional-essentialist areas).

The other egalitarian cluster contains 12 commuting zones and can be characterized as liberal-egalitarian. Areas in this cluster have the most egalitarian norms in the U.S. and include places such as Burlington, VT, Minneapolis, MN, and San Francisco, CA. While these commuting zones are highly egalitarian across all measures, there is some variation by indicator. Average age of first birth and gender segregation of college major stand out as the most prominent features characterizing liberal-egalitarian commuting zones. On average, women have their first child at older ages in these locales than in anywhere else in the U.S. To the extent that this reflects women's decision-making power, liberal-egalitarian commuting zones appear to be driven by ideals of women's independence. Educational fields of college degree are also more gender integrated in liberal-egalitarian commuting zones than other clusters, indicating that norms of gender essentialism are not as prevalent. There is also high levels of support for equal divisions of family labor and women's public sphere participation.

Examining differences in indicator means between the two egalitarian clusters (Table 1), we find that both share high levels of support for women in politics. This suggests that a common characteristic of gender egalitarian norms is the expectation that women may lead in the public sphere just as well as men. Differences in other indicator means were significant $(\mathrm{p}<.01)$ and effect sizes were generally moderate. The largest difference is in age of first birth, where women in liberal-egalitarian areas delay parenthood by over a year longer than those in egalitarian-essentialist locations. This further suggests that a defining characteristic of the liberalegalitarian cluster is greater ideals of women's independence. Moderate differences were also 
observed in the segregation of college majors and beliefs around the private sphere division of labor, indicating that norms of gender essentialism were least pronounced in liberal-egalitarian areas and that these locations also contained the greatest expectations that women and men contribute equally in the private sphere.

Results from the cluster analysis provide two key insights. First, despite being critiqued in previous research, a simplified framework dividing commuting zones into those with broadly defined egalitarian and traditional gender norms was found to provide a useful and empirically valid analytic tool. In particular, differences in expectations toward women's public sphere leadership emerged as a major point of divergence between egalitarian and traditional areas. Second, at greater detail we uncovered two types of traditional (traditional-essentialist and traditional-breadwinning) and two types of egalitarian (egalitarian-essentialist and liberalegalitarian) commuting zones. These divisions resonate with research highlighting the multidimensionality of gender norms by showing heterogeneity within each cluster in levels of the four indicators. Norms of gender essentialism emerged as one dimension characterizing a particular type of traditional (traditional-essentialist) and egalitarian (egalitarian-essentialist) commuting zone. Pronounced opposition to women's participation in the public sphere was an exceptional feature of traditional-breadwinner areas, while support for women's independence most characterized liberal-egalitarian locations.

\section{Compositional and Contextual Effects in Sustaining Spatial Variation in Gender Norms}

Having identified two sets of clusters that provide meaningful descriptions of local gender norms, we now examine whether this spatial variation is sustained by the composition of residents or the context of exposure to local norms. We focus on the four-cluster framework to provide a more detailed analysis of sub-national variation. Table B1 in the appendix reports 
descriptive demographic characteristics of each cluster. The largest differences between clusters are in educational and occupational composition. Liberal-egalitarian commuting zones are the most educated and have the largest proportion of workers in managerial/professional occupations, while traditional-essentialist areas have the lowest levels of these two characteristics. Traditional-breadwinner and egalitarian-essentialist areas are similar across most demographic characteristics, with levels of education and concentration of managerial/ professional occupations that are between liberal-egalitarian and traditional-essentialist locations.

To explore whether differences in demographic composition account for cluster variation in gender norms, we performed a series of regression models to identify the portion of cluster differences in individual-level gender norm indicators attributed to the uneven distribution of respondents with certain characteristics across clusters. Figure 4 illustrates the portion of cluster differences explained by these demographic characteristics. Full results are reported in the appendix, Tables $\mathrm{C} 1$ and $\mathrm{C} 2$. For the most part, there is little evidence for compositional effects. Demographic characteristics explained only 2 to 16 percent of significant cluster differences in attitudes toward women in politics and women's probability of majoring in science/engineering fields. There was some indication of compositional effects in mothers' age of first birth. For this indicator, demographic characteristics accounted for at least $30 \%$ of the between-cluster differences. The largest compositional effects were observed in the liberal-egalitarian cluster, where between 43 (between liberal-egalitarian and traditional-essentialist) and 55 (between liberal-egalitarian and egalitarian-essentialist) percent of the total effects were mediated by demographic covariates. Yet, even after accounting for demographics, differences between clusters remained significant, with respondents residing in liberal-egalitarian commuting zones predicted to delay parenthood an additional five months to a year longer than respondents living 
elsewhere $(\mathrm{p}<.05)$. Figure 4 also shows compositional effects with regards to views toward the gendered division of family labor. These effects are primarily constrained to liberal-egalitarian areas, where between 22 (between liberal-egalitarian and traditional-breadwinner) and 32 (between liberal-egalitarian and egalitarian-essentialist) percent of between-cluster differences were mediated by demographic controls. However, respondents in liberal-egalitarian areas are still predicted to be significantly more supportive of family gender equality even after accounting for demographics $(\mathrm{p}<.05)$.

To explore whether local gender norms are instead sustained by contextual effects, we compare outcomes for respondents with similar demographic characteristics across each cluster by adding interaction terms to the full-models used to examine demographic composition. Specifically, we explore whether educational differences vary by cluster in predicting individuallevel attitudes toward women in politics, mothers' age of first birth, and views toward the family division of labor. In examining the possession of a college degree in science/engineering fields, we explore whether the supply of science/engineering occupations has varying associations with women's field of study across clusters. For each gender norm indicator, evidence for the role of context would be found if the effects of these demographic characteristics vary by cluster, suggesting that individuals who would otherwise have egalitarian (traditional) outcomes, instead hold more traditional (egalitarian) characteristics as a result of the gender norms where they reside. 


\section{A. Disagree, Men Better Suited for Politics}
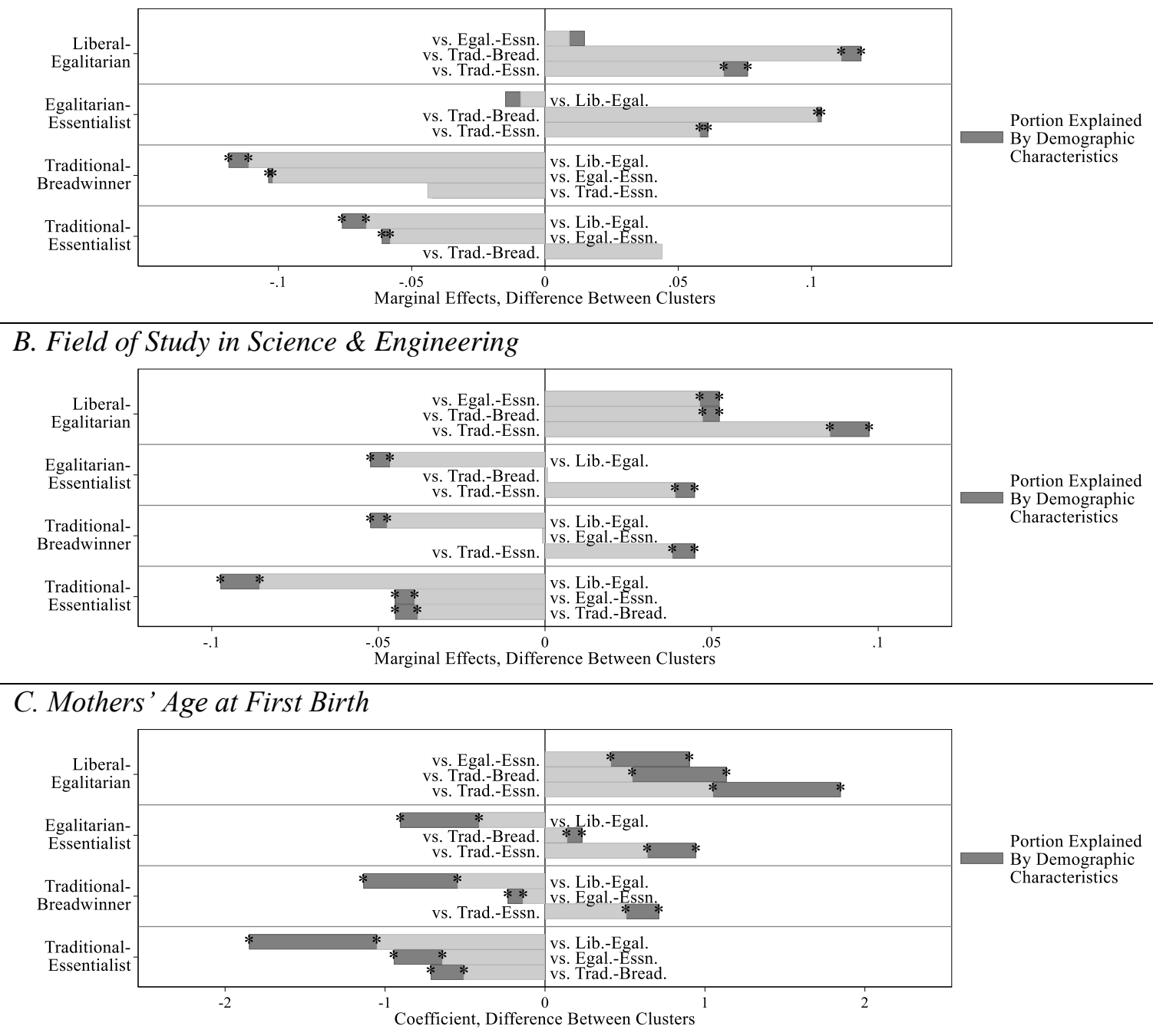

D. Level of Disagreement, Better for Men to Work, Women to Tend Home

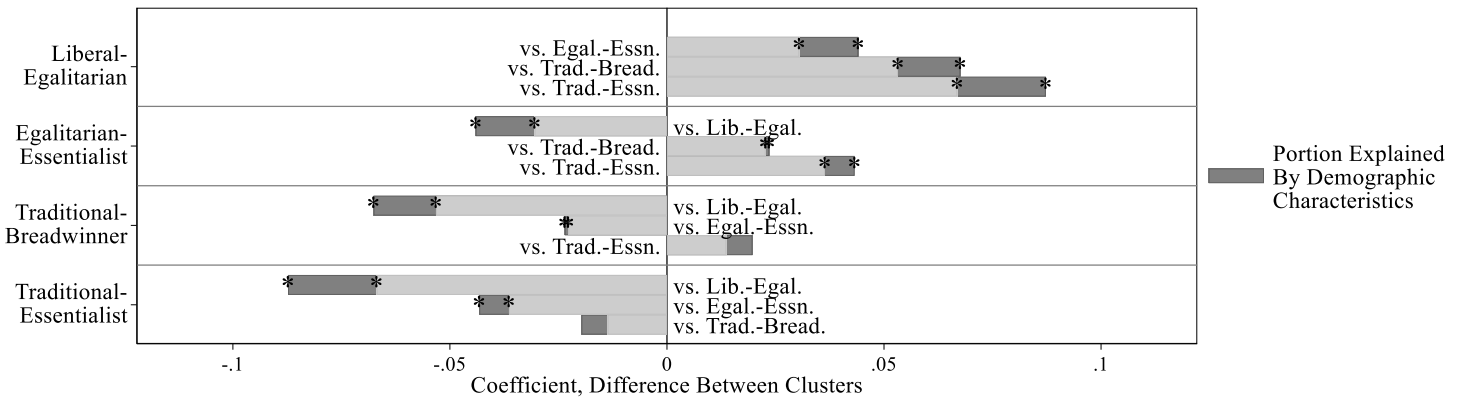

\section{FIGURE 4. Portion of Cluster Differences in Individual-Level Gender Norm Indicators Explained by Demographic Composition}

NOTE: Full results reported in appendix Tables C1 and C2. Portion explained by demographic characteristics calculated with a series of regression models. The first model identified cluster differences in individual-level outcomes with fixed effects for survey year and region. Cluster differences for this model are represented by the full length of each bar. The second model added demographic controls for gender, race, education, occupation, age, employment, and marital status. Cluster differences from this model are represented by the light gray bars. Differences in coefficients between the two models are used to estimate the portion explained by demographic characteristics. Logistic regression models were used for A and B, and OLS was used for $\mathrm{C}$ and D. Average marginal effects are used in A and B to account for unobserved heterogeneity affecting the scaling of $\log$ odds. ${ }^{*} \mathrm{p}<0.05$ for difference between specified clusters. 


\section{A. Disagree, Men Better Suited for Politics}

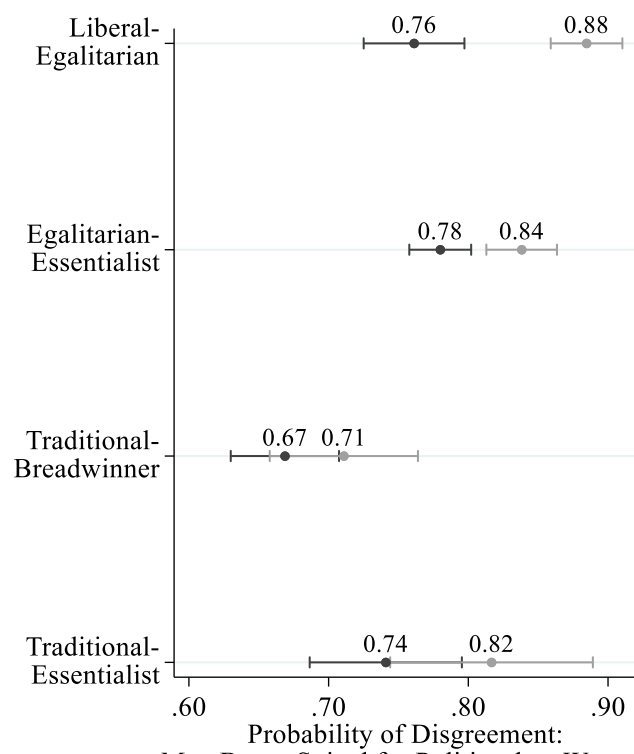

Men Better Suited for Politics than Women

- High School Degree or Less

- College Educated

\section{B. Field of Study in Science \& Engineering}

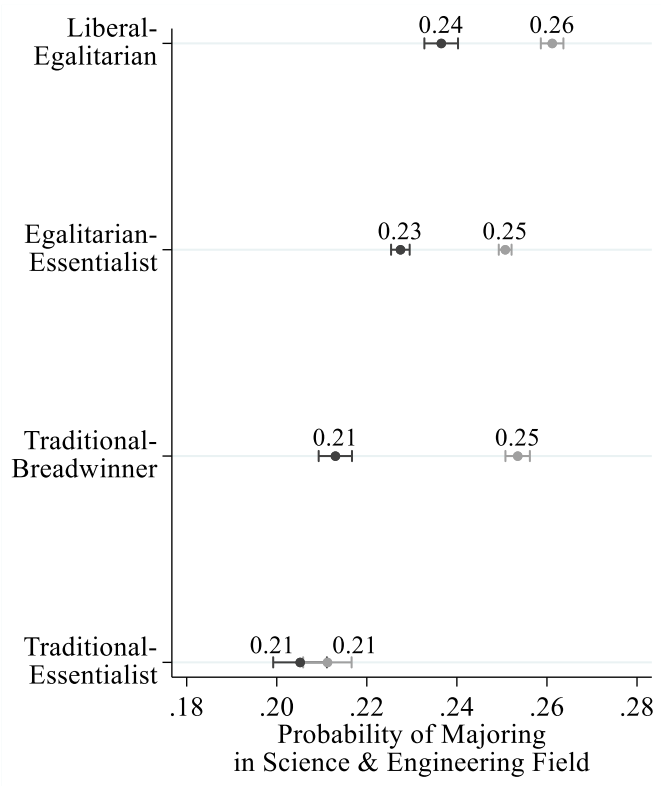

- $4 \%$ of Workers Emp. in Science/Engin. Occ.

- $6 \%$ of Workers Emp. in Science/Engin. Occ.

D. Level of Disagreement, Better for Men to

C. Mother's Age at First Birth

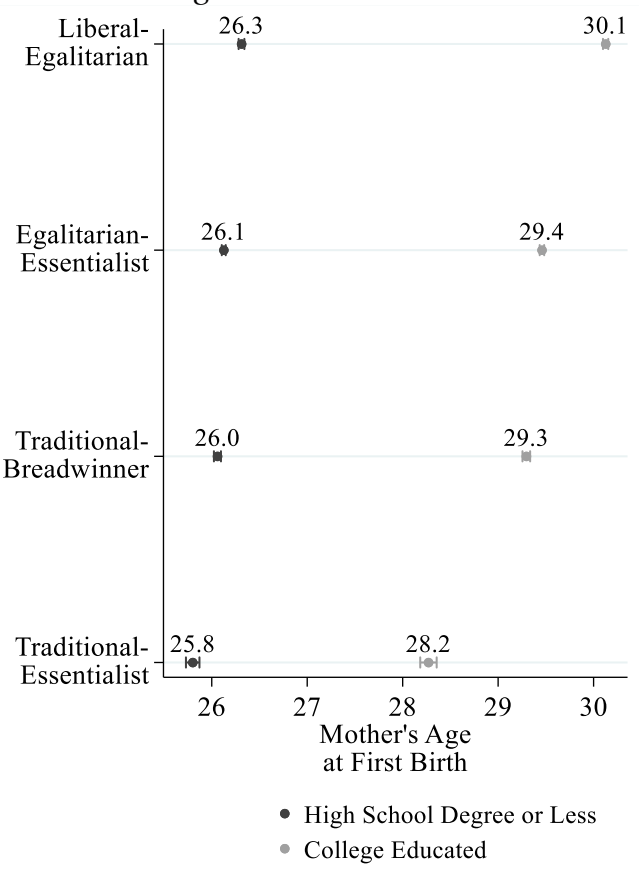

Work, Women to Tend Home

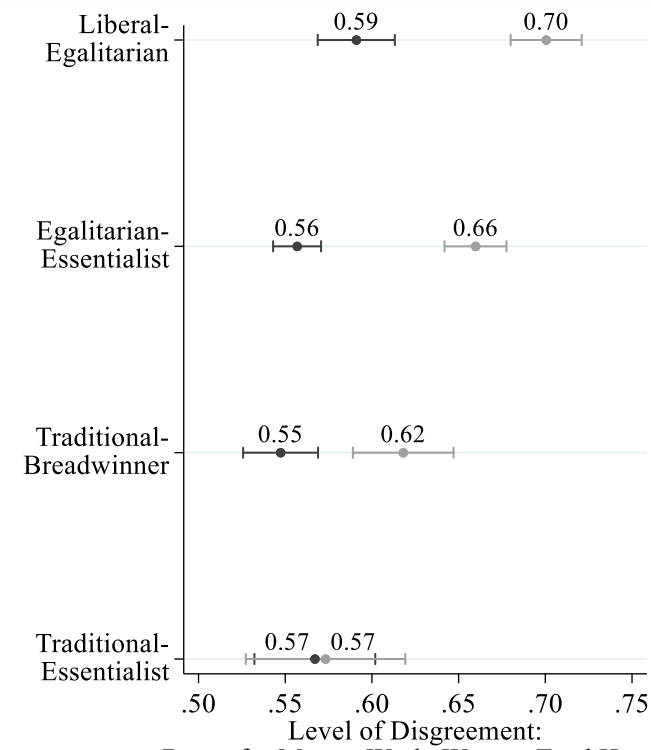

Better for Men to Work, Women Tend Home

- High School Degree or Less

- College Educated

FIGURE 5. Within-Cluster Differences in Demographic Predictors of Gender Norm Indicators, Testing Contextual Effects

NOTE: Coefficients surrounded by $95 \%$ confidence intervals, calculated from independent regression models predicting outcomes with the interaction of cluster and respondent education (A, C, and D) or share of commuting zone workers employed in science and engineering occupations (B). In B, coefficients plotted at $25^{\text {th }}$ and $75^{\text {th }}$ percentile of science/engineering occupational concentration. All models include additional controls for gender, race, occupation, age, employment status, marital status, and fixed effects for survey year and region. Full results reported in appendix, Tables C1 and $\mathrm{C} 2$. 
Figure 5 reports predicted outcomes for respondents with the same demographic characteristics across clusters (full results reported in appendix, Tables C1 and C2). Overall, the largest evidence for contextual effects is found in the most traditional clusters. Examining attitudes toward women in politics, the gap between high school or less and college educated respondents is smallest in the traditional-breadwinner cluster which had the highest level of traditionalism on this item (see Table 1). Both low- and high-educated respondents in this cluster held greater resistance to women in politics than respondents in other locations. This effect was strongest among the college educated, suggesting that the context of living in areas with traditional-breadwinning norms causes individuals who would otherwise hold egalitarian attitudes (e.g. the college educated) to be more traditional.

Evidence for contextual effects are also found in the traditional-essentialist cluster for the three additional indicators. Women in traditional-essentialist areas are similarly as likely to major in science/engineering fields regardless of the concentration of science/engineering occupations. In addition, the education gap in both mothers' age of first birth and views toward the gendered division of family labor is substantially smaller or non-existent in traditionalessentialist commuting zones, while being much larger in all other clusters. These patterns suggest that the experience of living with traditional-essentialist gender noms shapes respondents' behaviors and attitudes, even when individual characteristics (education) or economic settings (supply of science/engineering occupations) would lend themselves to different outcomes.

Figure 5 also illustrates limited evidence for compositional effects. In general, education gaps and gaps by the supply of science/engineering occupations were largest in the liberalegalitarian cluster. This is consistent with previously reported results (Figure 4) and suggests that 
demographic composition plays a meaningful role in the types of gender norms found in liberalegalitarian locations. Compositional effects were also observed in the traditional-breadwinner cluster with regards to women's probability of holding a bachelor's degree in a science/ engineering field. The gap between respondents residing in areas with a low- versus highconcentration of science/engineering occupations was twice as large as any other cluster. This suggests that one reason for the low levels of gender segregation in college majors within traditional-breadwinning areas is because these locations have a higher proportion of occupations drawing women who have studied similar fields as men.

In summary, we find that both contextual and compositional effects contribute to spatial variation in gender norms, but that context plays a more prominent role. This is particularly true in sustaining traditional norms, where contextual effects were pronounced in the cluster with the most traditional outcomes on each indicator. Compositional effects were most evident for liberalegalitarian commuting zones, suggesting that a large reason for these areas' progressive gender norms is the type of people (in particular, the highly educated) who reside there.

\section{CONCLUSION}

Our results highlight spatial variation in gender norms across U.S. commuting zones and offer two frameworks for conceptualizing this phenomenon. At a general level, commuting zones can be divided between those with traditional and egalitarian gender norms. This interpretation is consistent with previous research applying a unidimensional framework (Inglehart and Norris 2003) which assumes unified traditional or egalitarian expectations toward women and men across various aspects of society. Within that divide, there exists further heterogeneity through which more detailed dimensions of gender norms emerge. Norms of gender essentialism emerged as one dimension characterizing particular forms of traditionalism and egalitarianism. 
Opposition to women's participation in the public sphere was an exceptional feature of one group of commuting zones (traditional-breadwinner), while women's independence was a major characteristic of the most egalitarian areas (liberal-egalitarian). These more nuanced findings support multidimensional frameworks for describing gender norms. Yet, it is important to contextualize these complex dimensions as occurring within a more generalized divide between egalitarian and traditional environments.

Recognizing the complementarity between general and detailed models for local gender norms leads to the question of which framework researchers should use and when. We agree with scholars who have argued that nuance, while valuable, may not always be necessary (Healy 2017). Indeed, much research may not have sufficient data to measure multidimensional components of local gender norms. In such settings, a unidimensional approach treating areas as broadly egalitarian or traditional provides an empirically valid and parsimonious description of gender norms, if only at less detail. However, when data are available or if the problem is sufficiently complex (see Hirschman 1984), considering the multidimensional nature of local gender norms may be advantageous. This is particularly true when focusing on gender essentialism, women in leadership, or women's independence which emerged as dimensions differentiating types of egalitarian and traditional areas.

In addition to identifying the structure of local gender norms, we also examined the factors contributing to this spatial variation. In general, we found that both contextual and compositional effects play a role, but contextual effects appear to be more consequential. This is particularly true in traditional areas, where our results suggest that the experience of residing in traditional-breadwinning or traditional-essentialist locations shapes residents' attitudes and behaviors to align with their cultural environment. We also found some evidence that liberal- 
egalitarian gender norms are sustained by the composition of highly-educated residents. Yet, these areas remained more egalitarian than other commuting zones even after accounting for demographic composition, suggesting that while compositional effects play a role in these local norms, contextual experiences contribute as well.

Our findings highlight the importance of space in cultural dynamics related to gender. The places where individuals live have distinct gender norms that convey varying expectations toward women and men. The experience of residing in these contexts shapes individuals' attitudes and behaviors. This contextual effect is particularly strong in traditional environments, suggesting that remaining gender traditionalism in the U.S. has a strong geographic component. Although gender inequality is a global phenomenon, its manifestations are distinctly local. Consequently, efforts to advance equality more broadly may be most effective when focused on local change in the communities where we live and work.

\section{NOTES}

${ }^{1}$ Following previous research (Mandel 2009), we use Ward's linkage which aims to generate groups with minimal variance between units.

${ }^{2}$ These data come from the GSS Sensitive Datasets which provide geo-coded information on respondents. GSS Sensitive Data files were obtained under special contractual arrangements designed to protect the anonymity of respondents. These data are not available from the author. Persons interested in obtaining GSS Sensitive Data Files should contact the GSS at GSS@NORC.org. 
${ }^{3}$ We adjust for yearly change in attitudes toward women in politics with varying intercept (by commuting zone) logistic regression models. Year was treated categorically in these models to account for non-linear shifts.

${ }^{4}$ The U.S. Census Bureau (2020) recommends using ACS five-year samples when focusing on local geographies. These data pool five consecutive years of the ACS, which are intentionally sampled to ensure no respondents are surveyed twice and weighted to be nationally representative. County-level data on bachelor's degree field of study are not available for all counties in files for the one-year ACS.

${ }^{5}$ It is possible that college major selection reflects the location where a respondent is from, rather than where they reside, as individuals may choose an educational field during young adulthood. Unfortunately, our data do not identify respondents' childhood commuting zone that would allow us to test for this possibility. If it is the case that college major selection reflects the area where a respondent is from, we would expect our results to be even stronger after accounting for this dynamic where respondents' exposure to local gender norms in their childhood is reflected in their future area of study.

${ }^{6}$ We adjust for yearly change in this indicator using varying intercept (by commuting zone) regression models. Year was treated categorically in these models to account for non-linear shifts. 
${ }^{7}$ Robustness tests using alternative minimums of $1,20,50$, and 100 respondents were conducted, with substantive findings remaining consistent.

${ }^{8}$ We use average marginal effects because these are not affected by unobserved heterogeneity influencing the scaling of logistic regression coefficients (log odds) that invalidate betweenmodel comparisons (see Long and Mustillo 2018; Mood 2010).

\section{REFERENCES}

Abelson, Miriam. 2019. Men in Place: Trans Masculinity, Race, and Sexuality in America. Minneapolis, MN: University of Minnesota Press.

Autor, David H, and David Dorn. 2013. The Growth of Low-Skill Service Jobs and the Polarization of the US Labor Market. American Economic Review 103 (5): 1553-97.

Baizan, Pau, Bruno Arpino, and Carlos Eric Delclòs. 2016. The Effect of Gender Policies on Fertility: The Moderating Role of Education and Normative Context. European Journal of Population 32(1):1-30.

Barone, Carlo. 2011. Some Things Never Change: Gender Segregation in Higher Education across Eight Nations and Three Decades. Sociology of Education 84(2):157-76.

Brown-Saracino, Japonica. 2017. How Places Make Us: Novel LBQ Identities in Four Small Cities. Chicago, IL: University of Chicago Press.

Brusco, Michael J., Renu Singh, Dennis J. Cradit, and Douglas Steinley. 2017. Cluster Analysis in Empirical OM Research: Survey and Recommendations. International Journal of Operations \& Production Management 37 (3): 300-320. 
Charles, Maria. 2019. Gender Attitudes in Africa: Liberal Egalitarianism Across 34 Countries. Social Forces doi:10.1093/sf/soz132 .

Charles, Maria, and Karen Bradley. 2009. Indulging Our Gendered Selves? Sex Segregation by Field of Study in 44 Countries. American Journal of Sociology 114 (4): 924-76.

Charles, Maria, and David B. Grusky. 2004. Occupational Ghettos: The Worldwide Segregation of Women and Men. Stanford, CA: Stanford University Press.

Chatillon, Anna, Maria Charles, and Karen Bradley. 2018. Gender Ideologies. In Handbook of the Sociology of Gender, edited by Barbara J. Risman, Carissa M. Froyum, and William J. Scarborough. New York, NY: Springer.

Coleman, James S. 1994. Foundations of Social Theory. Cambridge, MA: Harvard University Press.

Correll, Shelley J., Cecilia L. Ridgeway, Ezra W. Zuckerman, Sharon Jank, Sara Jordan-Bloch, and Sandra Nakagawa. 2017. It's the Conventional Thought That Counts: How ThirdOrder Inference Produces Status Advantage. American Sociological Review 82 (2): 297 327.

Cotter, David, Joan M. Hermsen, and Reeve Vanneman. 2011. The End of the Gender Revolution? Gender Role Attitudes from 1977 to 2008. American Journal of Sociology 117 (1): 259-89.

Crossley, Alison Dahl. 2017. Finding Feminism: Millennial Activists and the Unfinished Gender Revolution. New York, NY: New York University Press.

Cutter, Gary. 2020. Effect Size or Statistical Significance, Where to Put Your Money. Multiple Sclerosis and Related Disorders 38:101490. 
Dickerson, Niki, Lisa Schur, Douglas Kruse, and Joseph Blasi. 2010. Worksite Segregation and Performance-Related Attitudes. Work and Occupations 37 (1): 45-72.

Dirksmeier, Peter. 2015. The Intricate Geographies of Gender Ideologies in Germany. Geoforum $64: 12-24$.

Dolan, Kathleen A. 2014. When Does Gender Matter?: Women Candidates and Gender Stereotypes in American Elections. Oxford, UK: Oxford University Press.

Dorn, David. 2009. Essays on Inequality, Spatial Interaction, and the Demand for Skills. Dissertation, University of St. Gallen no. 3613.

Evans, Alice. 2018. Cities as Catalysts of Gendered Social Change? Reflections from Zambia. Annals of the American Association of Geographers 108(4):1096-1114.

Evans, Alice. 2019. How Cities Erode Gender Inequality: A New Theory and Evidence from Cambodia. Gender \& Society 33(6):961-84.

Ferguson, Christopher J. 2009. An Effect Size Primer: A Guide for Clinicians and Researchers. Professional Psychology Research and Practice 40(5):532-38.

Florida, Richard. 2014. The Rise of the Creative Class--Revisited: Revised and Expanded. New York, NY: Basic Books.

Fowler, Christopher S. 2019. Labor-sheds for Regional Analysis. Shapefiles. Accessed May 15, 2018, (http://sites.psu.edu/psucz/data/).

Fowler, Christopher S., Leif Jenson, and Danielle Rhubart. 2019. Assessing U.S. Labor Market Delineations for Containment, Economic Core, and Wage Correlation. Https://Osf.Io/T4hpu/. 
Gallego, Aina, Franz Buscha, Patrick Sturgis, and Daniel Oberski. 2016. Places and Preferences: A Longitudinal Analysis of Self-Selection and Contextual Effects. British Journal of Political Science 46(3):529-50.

Gerson, Kathleen. 2009. The Unfinished Revolution: Coming of Age in a New Era of Gender, Work, and Family. Oxford, UK: Oxford University Press.

Geocorr, Geographic Correspondence Engine. 2018. Missouri Census Data Center. Accessed March 10, 2019 (http://mcdc.missouri.edu/applications/geocorr.html).

Gimpel, James G., Nathan Lovin, Bryant Moy, and Andrew Reeves. 2020. The Urban-Rural Gulf in American Political Behavior. Political Behavior https://doi.org/10.1007/s11109020-09601-w.

Goldscheider, Frances, Eva Bernhardt, and Trude Lappegård. 2015. The Gender Revolution: A Framework for Understanding Changing Family and Demographic Behavior. Population and Development Review 41 (2): 207-39.

Grunow, Daniela, Katia Begall, and Sandra Buchler. 2018. Gender Ideologies in Europe: A Multidimensional Framework. Journal of Marriage and Family 80(1):42-60.

Guenther, Katja. 2010. Making Their Place: Feminism After Socialism in Eastern Germany. Stanford, CA: Stanford University Press.

Healy, Kieran. 2017. Fuck Nuance. Sociological Theory 35 (2): 118-27.

Hirschman, Albert. 1984. Against Parsimony: Three Easy Ways of Complicating Some Categories of Economic Discourse. Bulletin of the American Academy of Arts and Sciences 37(8): 11-28.

Horne, Christine, and Stefanie Mollborn. 2020. Norms. Annual Review of Sociology 46(4):1-21. 
Inglehart, Ronald and Pippa Norris. 2003. Rising Tide: Gender Equality and Cultural Change Around the World. Cambridge, UK: Cambridge University Press.

Johnston, Professor Ron, Ron Johnston, Charles Pattie, and Charles Pattie. 2006. Putting Voters in Their Place: Geography and Elections in Great Britain. Oxford, UK: Oxford University Press.

Kabeer, Naila. 2002. The Power to Choose: Bangladeshi Women and Labor Market Decisions in London and Dhaka. New York, NY: Verso.

Kimes, Patrick K., Yufeng Liu, David Neil Hayes, and James Stephen Marron. 2017. Statistical Significance for Hierarchical Clustering. Biometrics 73(3):811-21.

Knight, Carly R., and Mary C. Brinton. 2017. One Egalitarianism or Several? Two Decades of Gender-Role Attitude Change in Europe. American Journal of Sociology 122 (5): 14851532.

Lesthaeghe, Ron. 2010. The Unfolding Story of the Second Demographic Transition. Population and Development Review 36(2):211-51.

Mandel, Hadas. 2009. Configurations of Gender Inequality: The Consequences of Ideology and Public Policy. The British Journal of Sociology 60 (4): 693-719.

Long, J. Scott, and Sarah A. Mustillo. 2018. Using Predictions and Marginal Effects to Compare Groups in Regression Models for Binary Outcomes. Sociological Methods \& Research https://doi.org/10.1177/0049124118799374.

Loop, Matthew Shane, and Leslie A. McClure. 2015. Testing for Clustering at Many Ranges Inflates Family-Wise Error Rate (FWE). International Journal of Health Geographics 14(1):4. 
Manson, Steven, Jonathan Schroeder, David Van Riper, and Steven Ruggles. IPUMS National Historical Geographic Information System: Version 14.0 [Database]. Minneapolis, MN: IPUMS. 2019. http://doi.org/10.18128/D050.V14.0

Maxwell, Rahsaan. 2019. Cosmopolitan Immigration Attitudes in Large European Cities: Contextual or Compositional Effects? American Political Science Review 113(2):456-74.

Maxwell, Rahsaan. 2020. Geographic Divides and Cosmopolitanism: Evidence From Switzerland. Comparative Political Studies 0010414020912289.

Meagher, Kelsey D., and Xiaoling Shu. 2019. Trends in U.S. Gender Attitudes, 1977 to 2018: Gender and Educational Disparities. Socius https://doi.org/10.1177/2378023119851692. Molotch, Harvey, William Freudenburg, and Krista E. Paulsen. 2000. History Repeats Itself, But How? City Character, Urban Tradition, and the Accomplishment of Place. American Sociological Review 65 (6): 791-823.

Mood, Carina. 2010. Logistic Regression: Why We Cannot Do What We Think We Can Do, and What We Can Do About It. European Sociological Review 26(1):67-82.

Pearse, Rebecca, and Raewyn Connell. 2016. Gender Norms and the Economy: Insights from Social Research. Feminist Economics 22(1):30-53.

Pepin, Joanna R., and David A. Cotter. 2018. Separating Spheres? Diverging Trends in Youth's Gender Attitudes About Work and Family. Journal of Marriage and Family 80 (1): 7-24.

Pessin, Léa. 2018. Changing Gender Norms and Marriage Dynamics in the United States. Journal of Marriage and Family 80(1):25-41.

Ridgeway, Cecilia L. 2011. Framed by Gender: How Gender Inequality Persists in the Modern World. Oxford, UK: Oxford University Press. 
Risman, Barbara J. 2004. Gender As a Social Structure: Theory Wrestling with Activism. Gender \& Society 18(4):429-50.

Ruggles, Steven, Sarah Flood, Ronald Goeken, Josiah Grover, Erin Meyer, Jose Pacas and Matthew Sobek. 2019. IPUMS USA: Version 9.0 [dataset]. Minneapolis, MN: IPUMS, 2019. https://doi.org/10.18128/D010.V9.0

Scarborough, William J., Ray Sin, and Barbara Risman. 2019. Attitudes and the Stalled Gender Revolution: Egalitarianism, Traditionalism, and Ambivalence from 1977 through 2016. Gender \& Society 33 (2): 173-200.

Shu, Xiaoling, and Kelsey D. Meagher. 2018. Beyond the Stalled Gender Revolution: Historical and Cohort Dynamics in Gender Attitudes from 1977 to 2016. Social Forces 96 (3): $1243-74$.

Smith, Tom W., Davern, Michael, Freese, Jeremy, and Hout, Michael, General Social Surveys, 1972-2016 [machine-readable data file]. Principal Investigator, Smith, Tom W.; CoPrincipal Investigators, Peter V. Marsden and Michael Hout; Sponsored by National Science Foundation. --NORC ed.-- Chicago: NORC, 2018: NORC at the University of Chicago [producer and distributor].

Taylor, Tiffany, Brianna Turgeon, Alison Buck, Katrina Bloch, and Jacob Church. 2019. Spatial Variation in U.S. Labor Markets and Workplace Gender Segregation: 1980-2005. Sociological Inquiry 89 (4): 703-26.

Thomas, Sue, and Clyde Wilcox. 2014. Women and Elective Office: Past, Present, and Future. Oxford, UK: Oxford University Press.

U.S. Census Bureau. 2012. Field of Bachelor's Degree in the United States: 2009. Washington, D.C. 
U.S. Census Bureau. 2020. "When to Use 1-Year, 3-Year, or 5-Year Estimates.” Retrieved June 5, 2020 (https://www.census.gov/programs-surveys/acs/guidance/estimates.html). 